\title{
Seeing Through Their Eyes: When Majority Group Members Take Collective Action on Behalf of an Outgroup
}

\author{
Robyn K. Mallett and Jeffrey R. Huntsinger \\ Loyola University Chicago
}

\section{Stacey Sinclair}

The University of Virginia

\section{Janet K. Swim}

The Pennsylvania State University

\begin{abstract}
We examined majority group members' collective action on behalf of a minority group, focusing on the role of outgroup perspective taking and group-based guilt. As expected, outgroup perspective taking was positively associated with heterosexuals' collective action in response to hate crimes against non-heterosexuals and Whites' action in response to hate crimes against Blacks (Studies 1 and 2). This association was partially mediated by group-based guilt (Studies 2 and 3). We also examined the role of group-based anger; although it directly related to collective action, it did not mediate the association between perspective taking and collective action. Finally, we manipulated outgroup perspective taking to demonstrate its causal role in the subsequent outcomes (Study 3).
\end{abstract}

KEYWORDS collective action, group-based anger, hate crime, identity, outgroup perspective taking, White guilt

Collective action can be a powerful force for social change. Women's right to vote, African American's civil liberties, and lesbian, gay and bisexual's growing equality are all the result of social movements. Nearly all research on participation in collective action has focused on predicting when individuals join groups that directly benefit themselves. For example, research has examined women's participation in feminist groups (Liss, Crawford, \& Popp, 2004), elderly individuals' participation in advocacy groups for the aged such as the Gray Panthers (Klandermans, 2002), and African Americans' participation in civil rights groups (McAdam, 1982). Yet people can participate in collective

\section{$\overline{\text { Author's note }}$}

Address correspondence to Robyn K. Mallett, Department of Psychology, Loyola University Chicago, 6525 N. Sheridan R., Chicago, IL 60626, USA [email: rmallett@luc.edu] 
action on behalf of groups they do not belong to. For example, Whites participated in the civil rights movement for Blacks, men participated in organizations to fight sexism against women, and heterosexuals participate in action through Gay-Straight Alliances and Gay, Lesbian, and Straight Education networks (Arsenault, 2006; Miceli, 2005). Because taking action on behalf of an outgroup is likely driven by reasons other than self-interest or own-group interest, existing research examining collective action that directly benefits the ingroup might not generalize to this phenomenon. The present research tests a model that explains majority group members' participation in collective action that benefits minority group members. Specifically, in the context of actual hate crimes, we examine how outgroup perspective taking and group-based guilt relate to heterosexuals' (Study 1) and Whites' (Study 2-3) participation in collective action on behalf of non-heterosexuals and Blacks, respectively. We also explore the role of ingroup identification and group-based anger in this process.

The majority of research on collective action has focused on factors that motivate disadvantaged group members to work toward change. For example, Taylor and McKirnan's (1984) fivestage model of intergroup relations describes changes in the relationship between advantaged and disadvantaged group members that spark the desire for social change. A shift occurs between stages 1 and 2 such that disadvantaged group members no longer perceive group differences as legitimate. The transition from stages 2 to 3 involves an increased focus on individual achievement and social mobility. If disadvantaged group members with high status try to gain acceptance into the advantaged group but are rejected, they may progress to stage 4 and attempt to raise the status of the entire disadvantaged group. Stage 5 results in a competitive style of intergroup relations. This model assumes that majority group members perceive the status difference as legitimate; however, a subset of majority group members may progress through this model in a manner similar to members of a disadvantaged group.

Collaboration between majority and minority group members can result in collective action that may produce significant social change for at least two reasons. First, the majority group member presence can be helpful because members of the majority often have more power than members of a disadvantaged minority (Sidanius \& Pratto, 1999; H. J. Smith \& Tyler, 1996). Second, collective action by majority group members may be more persuasive than collective action by minority group members. Research on interpersonal confrontation of discrimination shows that majority group members are more persuasive to the ingroup than are minority group members because majority group members are not perceived as direct beneficiaries of their action (Czopp \& Monteith, 2003; Jones, 1976). Thus, majority group members can send a powerful and persuasive message to other majority group members when they take action on behalf of a minority outgroup.

Yet it is easy for majority group members to not take action to ensure the rights of other groups. After all, collective action requires time and energy, and can be perceived as offering little in the way of personal gain-especially when the benefits are for members of a different group. Additionally, majority group members usually do not personally experience the same types of negative events that trigger collective action in disadvantaged minority group members. Among the disadvantaged, triggers of collective action might range from critical incidents such as the assassination of a political leader or failure to pass equal rights legislation, to myriad smaller disadvantages that accumulate until they reach a tipping point (Taylor \& McKirnan, 1984; Wright \& Tropp, 2002). Once triggered, disparate treatment is no longer tolerable, and disadvantaged group members work to fight for change on behalf of the ingroup as a whole. Because majority group members are usually not personally affected by such trigger events, a different process is needed to explain their participation in collective action on behalf of the disadvantaged outgroup.

Given the importance of majority group members' participation in collective action on behalf of minority group members and the dearth of research examining this phenomenon, we sought to propose an account of why this may 
occur. Drawing upon research on perspective taking, emotion, and helping behavior at the individual level, we expect outgroup perspective taking and group-based guilt to work in concert to explain outgroup helping behavior (i.e. collective action). Specifically, we expect that taking the perspective of an outgroup will lead majority group members to experience groupbased guilt and participate in collective action on behalf of that outgroup. Later we describe the empirical basis for each proposed link.

\section{Perspective taking and collective action}

There are at least two reasons to expect perspective taking will lead to action on behalf of an outgroup. First, existing research suggests that taking the perspective of an outgroup member increases positive evaluations of that individual and the group more generally (Batson et al., 1997; Dovidio et al., 2004; Galinsky \& Moskowitz, 2000; Vescio, Sechrist, \& Paolucci, 2003). It is reasonable to expect that people are more likely to engage in collective action on behalf of liked, as opposed to disliked, groups. Second, and perhaps more importantly, perspective taking at the individual level is a key antecedent of helping others (Batson, 1998; Underwood \& Moore, 1982). For example, participants who took the perspective of a recently orphaned fellow student volunteered more time to help the student than participants who did not take her perspective (Coke, Batson, \& McDavis, 1978). Although not yet empirically tested, a similar association may also exist at the group level, whereby taking the outgroup perspective increases the likelihood of helping the outgroup by participating in collective action that benefits them.

\section{Group-based guilt and collective action}

Group-based emotions, especially guilt, may also directly lead to collective action and be a means by which outgroup perspective taking indirectly leads to action. According to perspectives including intergroup emotions theory (E. R. Smith, 1993), emotions may be experienced at both the individual and group level (Branscombe, Doosje, \& McGarty, 2002). At the individual level, guilt results when an individual accepts personal responsibility for an action or inaction that results in the suffering of another (Estrada-Hollenbeck \& Heatherton, 1998). At the group level, one need not accept personal responsibility but the ingroup must be seen as responsible for mistreating another group, the mistreatment must have produced an existing disparity, and efforts to repair the damage must be seen as possible in order for group-based guilt to arise (Branscombe et al., 2002; Mallett \& Swim, 2004). Research at both the individual and group levels reveals that specific emotions correspond to unique behavioral responses; feelings of guilt tend to motivate reparation (Doosje, Branscombe, Spears, \& Manstead, 1998; Frijda, 1988; Mackie, Devos, \& Smith, 2000). For example, White Americans' feeling of group-based guilt for harming African Americans is associated with support for affirmative action policies (Iyer, Leach, \& Crosby, 2003; Swim \& Miller, 1999) and for opposition to future aggression against the outgroup (Maitner, Mackie, \& Smith, 2006). In addition to supporting reparative policies and suppressing future aggression, we expect that group-based guilt might also prompt majority group members to spend time and energy taking action on behalf of the outgroup.

Outgroup perspective taking should also indirectly lead to participation in collective action via feelings of group-based guilt. At the individual level, perspective taking is associated with feelings of guilt (Leith \& Baumeister, 1998). At the group level, majority group members who take an outgroup's perspective may begin to understand the outgroup's suffering, and perhaps consider the role that the majority group plays in harming the minority group (Zebel, Doosje, \& Spears, 2008. Perceiving ingroup responsibility and outgroup suffering may produce feelings of group-based guilt (Branscombe et al., 2002; Mallett \& Swim, 2007). If group-based guilt occurs, it could be sufficient to motivate majority group members to alleviate guilt by engaging in reparative action on behalf of minority group members (Doosje et al., 1998; Swim \& Miller, 1999). Therefore, we expect that feelings of 
group-based guilt will mediate the association between outgroup perspective taking and participation in collective action. We may find only partial, rather than full, mediation because guilt tends to be experienced at a moderate level (Swim \& Miller, 1999) and because guilt may not be the only emotion associated with outgroup perspective taking. Later we discuss the possibility that group-based anger might also occur.

\section{The possible role of ingroup identification}

In addition to testing our proposed model we explore the role of ingroup identification in the aforementioned process. In a series of studies Zebel et al. (2008) asked Dutch participants to imagine themselves as slaves or not and then evaluate scenarios about the Dutch slave trade. Imagining themselves as slaves was positively associated with reports of group-based guilt, but only among participants with low levels of Dutch identification. Moreover, guilt was related to support for a government apology, though unrelated to financial compensation. Although Zebel et al.'s work did not study collective action and found mixed support for attempts to repair intergroup relations, it does provide initial support for the role of perspective taking in majority group members' feelings of group-based guilt. Their research also suggests the possibility that high and low identified members of a group might show differences in the experience of group-based guilt if encouraged to take the perspective of an outgroup.

Based on these preliminary findings, it is possible that taking the outgroup perspective might initiate guilt, and subsequently collective action, more for some people than others. Specifically, as also proposed by Zebel et al. (2008), the effects of outgroup perspective taking on group-based guilt and collective action may depend upon the extent to which majority group members are identified with their ingroup. Engaging in outgroup perspective taking may entail negative thinking about the ingroup. People who are highly identified with the ingroup resist threats to the positive image of the ingroup, and tend to report feeling little group-based guilt
(Doosje, et al., 1998). Consequently, the degree to which one is identified with the ingroup may moderate the influence of perspective taking on feelings of group-based guilt (Zebel et al., 2008) and participation in collective action.

Our research goes beyond that of Zebel et al. in four ways. First, we examine responses to contemporary intergroup conflict as opposed to past wrongdoing. Considering examples of current conflict might inspire greater feelings of group-based guilt compared with thinking about past transgressions (Branscombe et al., 2002) and greater feelings of guilt might inspire effortful behavior such as participation in collective action. Second, we evaluate outgroup perspective taking by examining the way people naturally interpret events (Studies 1 and 2) and by instructing participants to take the outgroup's perspective (Study 3). We might find that the same model holds for spontaneous and deliberate perspective taking. Alternatively, deliberate perspective taking might prompt a more defensive mindset than spontaneous perspective taking and thus make ingroup identification more relevant to the process. Third, we examine actual behavior in response to discrimination rather than support for a government apology that may not personally affect outgroup members. Fourth, although Zebel et al.'s data are consistent with a mediation model, they do not test mediation. We test a full model of associations between outgroup perspective taking, group-based guilt, and participation in collective action, thereby increasing understanding of majority group members' motivation to act on behalf of an outgroup.

\section{The possible role of group-based anger}

We also explore the possibility that groupbased anger influences collective action on behalf of an outgroup. It is difficult to make clear predictions regarding the role of group-based anger because there is considerably less research on group-based anger than group-based guilt. However, we know that at the individual level, anger results from determining that an external agent is responsible for a transgression against oneself or another party (Lazarus, 1991). At the 
group level, feelings of anger elicit a desire to confront, oppose or argue against the agent (an individual or group) who is responsible for a blameworthy action (Devos, Silver, Mackie, \& Smith, 2002; Frijda, 1986; Iyer, Schmader, \& Lickel, 2007; Mackie et al., 2000). Research shows that Germans experienced anger when they perceived that their government had mistreated a disadvantaged outgroup (Montada \& Schneider, 1989) and that group-based anger predicted collective action on behalf of the ingroup (van Zomeren, Spears, Fischer, \& Leach, 2004). Indeed, Leach, Snider, and Iyer (2002) hypothesize that group-based anger might be a more powerful predictor of collective action than group-based guilt.

Yet there is reason to question the ability of group-based anger to motivate action on behalf of an outgroup, especially in comparison with group-based guilt. The extent to which groupbased anger and group-based guilt motivate action likely differs because of the typical target of each emotion. Anger tends to direct action against the perpetrating agent rather than on behalf of the harmed group. Therefore, if collective action is construed as a way to repair damaged intergroup relationships rather than as a way to punish the blameworthy party, anger might not motivate collective action as strongly as guilt, or at all. Further, group-based guilt is a reflective emotion and group-based anger is a reactive emotion (Baumeister, Reis, \& Delespaul, 1995; Leach, Iyer, \& Pedersen, 2006; Ortony, Clore, \& Collins, 1988). Reflective emotions might be more likely to motivate action on behalf of another group, whereas reactive emotions might be more likely to motivate action against a particular group. Given the divergent perspectives on the power of group-based anger and guilt to predict collective action on behalf of an outgroup, we simultaneously examine groupbased guilt and anger to determine their relative power to predict collective action.

We also test whether outgroup perspective taking indirectly leads to participation in collective action via feelings of group-based anger. Finlay and Stephan (2000) found that when Whites took the perspective of an African American who expressed anger about discrimination, they reported feeling angry. At the group level, majority group members who take an outgroup's perspective may consider the role that an external agent, such as the government or university administration, plays in harming the minority group. Perceiving outgroup suffering along with attributing responsibility to a university administration may produce feelings of anger (Leach et al., 2002). If outgroup perspective taking and group-based anger are each directly related to participation in collective action, then feelings of group-based anger might also mediate the relationship between perspective taking and action.

\section{Overview of studies}

Three studies tested a preliminary model of the role of outgroup perspective taking and group-based guilt in majority group members' participation in collective action on behalf of an outgroup. In Study 1, we examined the prediction that spontaneously taking the outgroup perspective was directly related to participation in collective action on behalf of that group. Study 2 replicated the direct effect of perspective taking on action, tested the direct effect of group-based guilt on collective action, and tested whether feelings of group-based guilt mediated the relationship between perspective taking and action. Finally, in order to resolve ambiguity regarding the direction of the effects demonstrated, in Study 3 we manipulated perspective taking, thereby demonstrating its causal role in the subsequent processes. In addition, in each study we explored whether ingroup identification moderated the positive effects of outgroup perspective taking on willingness to participate in collective action. We also tested the direct and indirect role of group-based anger in collective action on behalf of an outgroup (Studies 1, 2).

In all three studies, participants considered actual instances of hate crimes that targeted nonheterosexuals (Study 1) and Blacks (Studies 2 and 3 ) in their university community-a surprisingly pervasive problem given advances in civil rights that have occurred over the years (Herek, Cogan, \& Gillis, 2002). Unlike past 
research that typically examines policy support or, at most, self-reported willingness to engage in collective action, in the first two studies we analyze self-reports of actual participation in collective action.

\section{Study 1}

The main purpose of this study was to test a central prediction of our model; that outgroup perspective taking would be related to participation in collective action on behalf of that group. We examined this question within the context of an incident of intergroup conflict that occurred on a college campus. Lesbian, gay, and bisexual (LGB) student leaders received emails and phone calls that threatened their lives. In response, some students engaged in collective action to protest the attacks and demand social change from the administration. The administration responded to the collective student effort by pledging to enact university policies to improve intergroup relations on campus for LGB students. Thus, this incident provided an opportunity to study actual participation in collective action rather than support for apology or other indirect measures of attempts at social change.

The secondary purpose of the study was to explore the role of ingroup identification and group-based anger in this process. Because past research has found that ingroup identification moderates the influence of deliberate perspective taking (Zebel et al., 2008), in the present study we also examined how it was related to spontaneous perspective taking. Further, we examined whether feelings of group-based anger were directly related to collective action.

\section{Method}

Participants We gave 275 heterosexual participants (146 female, 118 male, 11 did not report gender) course credit for the present study. Participants indicated their sexual orientation in response to an item that read, 'On the following scale, chose the step that best describes your own sexual orientation,': 1 , exclusively heterosexual; 2, predominantly heterosexual, incidentally homosexual; 3, equally heterosexual and homosexual; 4 predominantly homosexual, but more than incidentally heterosexual; 5 , predominantly homosexual, incidentally heterosexual; and 6, exclusively homosexual. Participants who chose the number 1 were included in the analysis (137 female, 109 male, 6 did not report gender).

Materials and procedure All measures were completed on the Internet. ${ }^{1}$ Participants first completed an 18-item measure of heterosexual identification (Swim \& Mallett, 2005, see Appendix for a list of items) so we could test whether ingroup identification moderated the influence of perspective taking on collective action. Items were answered using a scale from 1 , not at all to 7 , very much $(M=4.27, S D=.76)$. We averaged participants' responses to these items to form a measure of ingroup identification $(\alpha=.80)$.

Participants then read a summary of events surrounding a hate crime against LGB students, along with the following instructions based on McPherson and Janoff-Bulman's (2000) study of perspective taking:

Now that you have been thinking about the events that led to the current LGB climate on campus, we would like to know more about your personal reactions to this situation. Please describe in your own words your thoughts and feelings about the (1) incidents that occurred, (2) the way in which the students responded, and finally (3) how the administration reacted.

Unlike other research that measures dispositional perspective taking (Davis, Conklin, Smith, \& Luce, 1997) or intentionally manipulates perspective taking by asking participants to put themselves in the shoes of a character in a scenario (Galinsky \& Moskowitz, 2000), we assessed the number of times that participants spontaneously took the perspective of LGB students in their written response to the hate crime and its surrounding events. We first divided each written response into coding units that reflected thought or phrase breaks $(M=6.32$, $S D=2.93$ for the number of written statements; see McPherson \& Janoff-Bulman, 2000 for more detail). Then, two trained research assistants determined whether or not each unit of the 
participant's writing took the perspective of the LGB students and expressed understanding of the consequences of the hate crime for targets of discrimination. An example of taking the LGB students' perspective is, "I understand how the death threats interrupted LGB students' life on campus, it must have been really upsetting." We averaged the coders ratings' of the total number of times the participant took the perspective of LGB students in their written responses to obtain a measure of outgroup perspective taking $(M=.92, S D=.93$; intraclass correlation coefficient $=.89$ ) .

We were also interested in whether feelings of group-based anger might be directly related to collective action, so we coded the spontaneous written responses for the amount of anger expressed at the university administration. Ratings of anger expression ranged from 0 , not at all to 4 , very much $(M=.48, S D=.68$; intraclass correlation coefficient $=.93)$. We believe that this provides a somewhat indirect measure of expressions of anger at a blameworthy agent, in this case, the university administration.

Heterosexual participants then answered yes or no to five questions that represented various types of collective action that they might have taken on behalf of LGB students in response to the hate crime ("I attended meetings of LGB groups;" "I attended ALLIES Straight But Not Narrow Program;" "I attended a lecture or presentation by an LGB person or gay rights activist;" "I attended the rally on September 14, 2002;" "I attended the conference on September 13-15, 2002"). These activities were aimed at formulating a plan for the university to respond to hate crimes and therefore serve as a measure of collective action on behalf of an outgroup. We summed the 'yes' answers to each of the five behaviors for each participant and divided the sum by five to create an average score for participation in collective action. ${ }^{2}$ Observed scores on the collective action item ranged from 0 to 4 $(M=.15, S D=.09)$.

\section{Results and discussion}

We calculated the correlation between all variables included in the Study 1 analyses. Correlations ranged from non-significant to moderate, and were in the expected direction (see Table 1, above the diagonal).

We conducted two transformations on the data before estimating the remaining analyses. First, we centered the variables. Second, the distribution of participation in collective action was slightly positively skewed. We used a square root transformation to correct the positive skew prior to the reported analyses. Results for the untransformed variable are nearly identical to those for the transformed variable; this is true for Studies 1 and 2.

Perspective taking We expected outgroup perspective taking to be related to heterosexuals' participation in collective action on behalf of non-heterosexuals. To examine this prediction, we regressed collective action on outgroup perspective taking. Because some research has found gender differences in helping behavior (Batson, 1998), we included gender as a covariate in all analyses. ${ }^{3}$ As predicted, perspective taking and collective action were positively related,

Table 1. Correlations between the variables used in Studies 1 and 2. Correlations above the diagonal represent Study 1 and correlations below the diagonal represent Study 2

\begin{tabular}{lccccc}
\hline & $\begin{array}{c}\text { Ingroup } \\
\text { identification }\end{array}$ & $\begin{array}{c}\text { Outgroup } \\
\text { perspective } \\
\text { taking }\end{array}$ & $\begin{array}{c}\text { Group-based } \\
\text { anger }\end{array}$ & $\begin{array}{c}\text { Group-based } \\
\text { guilt }\end{array}$ & $\begin{array}{c}\text { Collective } \\
\text { action }\end{array}$ \\
\hline Ingroup identification & - & $-.13^{*}$ & -.01 & - & .10 \\
Outgroup perspective taking & -.09 & - & $.14^{*}$ & - & $.24^{* * *}$ \\
Group-based anger & .02 & .05 & - & - & $.18^{* *}$ \\
Group-based guilt & $-.19^{* * *}$ & $.34^{* * *}$ & .08 & $.18^{* *}$ & - \\
Collective action & -.05 & $.20^{* * *}$ & $.15^{*}$ & - \\
\hline
\end{tabular}

$* p<.05 ; * * p<.01 ; * * * p<.001$. 
$\beta=.26, t(217)=3.89, p<.001$. As heterosexuals' spontaneous reports of outgroup perspective taking increased, reports of participation in activities to improve the status of non-heterosexuals increased. To our knowledge, this is the first empirical demonstration that outgroup perspective taking is related to collective action on behalf of an outgroup. In fact, we found no studies that assessed the association between perspective taking and any type of collective action.

We then examined whether ingroup identification moderated the relationship between perspective taking and participation in collective action. In the first step of the analysis, we regressed collective action on participant gender, ingroup identification, and perspective taking. This step was significant, $R^{2}=.10, F(2,220)=7.59$, $p<.001$. Specifically, we found an association between identification and participation in collective action, $\beta=.24, t(220)=3.59, p<.001$. As identification with heterosexuals increased, so did action on behalf of non-heterosexuals. The finding is somewhat surprising because ingroup identification, particularly for high status group members, might be expected to lead to minimizing rather than acknowledging the struggles faced by outgroup members. A positive association between identification and collective action could be unique to group memberships such as sexual orientation because the majority of heterosexuals rarely consider what it means to be heterosexual. Those who have thought about their sexual orientation might represent a different type of heterosexual, one who thinks about the impact of sexual orientation on life more generally, and one who is therefore more likely to help the outgroup.

In the second step, we added the product of identification and perspective taking to the model. This step was not significant, $R^{2}=.09$, $F(2,220)=6.47, p=n s$; identification did not moderate the effect of spontaneous perspective taking on collective action, $\beta=.11, t(220)=1.70$, $p=n s$. In other words, identification with the ingroup did not increase or decrease the association between spontaneous outgroup perspective taking and participation in collective action. ${ }^{4}$ Of course, this lack of association may also be a function of the unique meaning associated with individuals who identify with heterosexuals. It is also possible that spontaneous perspective taking differs from deliberate perspective taking in the extent to which it prompts defense of the ingroup.

Group-based anger We also examined whether the amount of anger expressed at the administration was directly related to collective action. We regressed participation in collective action on gender and the amount of anger expressed at the university administration. We found an association between anger at the administration and collective action, $\beta=.18, t(220)=2.70$, $p=.007$. As heterosexuals' expressions of anger at the university administration increased, so did reports of participating in activities to improve the status of non-heterosexuals.

We next investigated whether group-based anger mediated the relationship between outgroup perspective taking and collective action. We followed Baron and Kenny's (1986) recommendations for testing mediation, which involves four steps. Again, we included gender as a covariate in the analyses. First, the predictor (perspective taking) was related to the mediator (anger at the administration), $\beta=.15$, $t(220)=2.23, p=.03$. Second, as reported earlier, the predictor (perspective taking) was related to the dependent variable (collective action). Controlling for the predictor, the mediator was related to collective action, $\beta=.14, t(220)=2.18$, $p=.03$. Controlling for the mediator, the predictor was related to collective action, $\beta=.24$, $t(220)=3.59, p<.001$. However, the indirect effect (Sobel, 1982) of perspective taking on collective action was not significant $(z=.32$, $p=n s)$. Therefore, anger at the university administration did not partially mediate the relationship between spontaneous outgroup perspective taking and collective action.

In sum, the results of Study 1 suggest that, consistent with our proposed model, outgroup perspective taking is related to prosocial behavior at the group level; stepping into the shoes of an outgroup is directly related to collective action 
to aid that group. Additional analyses showed that anger at the administration for their response to the hate crime was also related to collective action on behalf of non-heterosexuals. However, group-based anger did not mediate the association between outgroup perspective taking and collective action. Finally, ingroup identification did not moderate the relationship between spontaneous perspective taking and collective action.

\section{Study 2}

In Study 1, we established that spontaneous outgroup perspective taking is related to majority group members' collective action on behalf of minority group members. In Study 2, we tested the principal route through which we expected perspective taking to influence participation in collective action. Specifically, we assessed the associations between outgroup perspective taking, group-based guilt, and collective action on behalf of an outgroup. As in Study 1, we explored these questions within the context of an actual incident of intergroup conflict that occurred on a college campus. In this instance, African American student leaders were the targets of intimidation and death threats. Students responded by engaging in collective action to demand resolution from the administration. The administration countered by drafting a proposal to enact university policies that would improve intergroup relations on campus, especially for minority group members. We expected to find (i) a positive association between outgroup perspective taking and White's participation in collective action on behalf of Blacks, (ii) a positive association between White guilt and collective action, and (iii) that group-based guilt at least partially mediated the relationship between outgroup perspective taking and collective action.

As in Study 1, we also explored the roles of ingroup identification and group-based anger in this process. Based on the results of Study 1, we do not expect ingroup identification to moderate the relationship between spontaneous perspective taking and collective action.
Also based on Study 1, we suspect that groupbased anger will be directly related to collective action but not mediate the association between perspective taking and action, with or without the inclusion of group-based guilt.

\section{Method}

Participants For the hate crime targeting Blacks, students enrolled in an introductory psychology course (183 females, 142 males) completed all measures in large group testing sessions. Students of several ethnic/racial backgrounds participated in the study, but only members of the majority group, Whites (139 females, 110 males), are included in the analysis.

Materials and procedure Participants first reported the extent to which they identified with Whites using 18 items (Swim \& Mallett, 2005; see Appendix). Items were answered using a scale from 1 , not at all to 7 , very much $(M=4.34$, $S D=.76)$. We averaged participants' responses to these items to form a measure of ingroup identification $(\alpha=.85)$.

Next, Whites were presented with a summary of events surrounding a hate crime against Blacks, read the same instructions based on McPherson and Janoff-Bulman's (2000) study of perspective taking, and wrote the same type of response in terms of their reactions to the events. Trained coders used the same coding scheme to assess the number of times that Whites took the perspective of Black students. We averaged the coders' ratings of the frequency of perspective taking; inter-rater reliability for the coding was good (intraclass correlation coefficient $=.92$, $M=2.72, S D=1.58)$.

As in Study 1, we used the same procedure to code the written responses for the amount of anger expressed at the university administration. Ratings of anger expressed in the essay ranged from 0 , not at all to 4 , very much $(M=.60$, $S D=.85$; intraclass correlation coefficient $=.93$ ) . Participants then completed the five-item White guilt scale (Swim \& Miller, 1999), composed of items like 'I feel guilty about the past and present social inequality of Black Americans 
(i.e. slavery, poverty).' Items were answered on a scale from 1, not at all guilty to 7, very guilty $(\alpha=.87, M=3.42, S D=1.48)$.

Finally, White participants indicated whether they participated in eight types of collective action to benefit Blacks. Items included, 'I attempted to/succeeded at rushing the field at the Blue and White game;' 'I attended the rally held by students, at 9:00 pm at the HUB on April 21st;' 'I attended the NO HATE AT PENN STATE rally at Old Main on April 24th at 4:00 pm;' 'I spent the night at the HUB as part of the Village;' 'I visited the Village, at the HUB;' 'I wrote letters to the editors of the Daily Collegian, Centre Daily Times, or any other newspaper or news organization (regardless of whether they were published);' 'I attended the rally on September 14, 2001;' 'I attended the conference on September 14-16, 2001.' Participants answered yes or no for all items. Again, all actions were aimed at improving the state of intergroup relations for Black students. Therefore for Whites, this serves as a measure of collective action on behalf of an outgroup. We summed the 'yes' responses for each participant and divided the sum by eight to produce an average score for participation in collective action. Observed scores for collective action ranged from 0 to $8(M=.17, S D=.15)$.

\section{Results}

We calculated the correlations between all variables used in Study 2. As in Study 1, correlations ranged from non-significant to moderate, and were in the direction expected by past research (see Table 1, below the diagonal).

As in Study 1, we conducted two transformations on the data before estimating the remaining analyses. First, we centered the variables. Second, we again found that the measure of collective action was slightly positively skewed so we performed a square root transformation before conducting the analyses.

Perspective taking To determine whether outgroup perspective taking was directly related to participation in collective action, we regressed participation in collective action on outgroup perspective taking, controlling for gender. We found the predicted relationship between perspective taking and collective action, $\beta=.17, t(228)=2.54, p=.01$. As in Study 1 , as spontaneous outgroup perspective taking increased, so did reports of participation in collective action.

To determine whether ingroup identification moderated this relation, in step 1 we regressed collective action on participant gender, ingroup identification, and perspective taking. Unlike Study 1 , this step was not significant, $R^{2}=.07$, $F(2,228)=5.71, p=n s$. Ingroup identification was not directly related to collective action, $\beta=-.06, p=n s$. This result lends further support to the speculation that there might be something unique about identification with a sexual orientation group as opposed to a racial or gender group.

We added the product of identification and perspective taking in step 2. As in Study 1, this step was not significant, $R^{2}=.07, F(2$, $228)=5.71, p=n s$. Ingroup identification did not moderate the relationship between spontaneous perspective taking and collective action, $\beta=-.04, p=n s^{5}$

Group-based guilt We continued testing the proposed model by determining whether feelings of group-based guilt were directly related to participation in collective action by regressing participation in collective action on White guilt, controlling for gender. As expected, White guilt and collective action were positively related, $\beta=.18, p<.01$. As reports of White guilt increased, so did participation in collective action.

Mediation In addition to predicting that perspective taking and group-based guilt would directly relate to collective action on behalf of an outgroup, our model suggests that groupbased guilt would at least partially mediate the relationship between perspective taking and action. To examine this prediction, we followed Baron and Kenny's (1986) recommendations for testing mediation. Table 2 shows the results of this analysis. As expected, feelings of White guilt partially mediated the relationship between spontaneous outgroup perspective taking and 
Table 2. White guilt mediates the association between perspective taking and participation in collective action in Study 2

\begin{tabular}{|c|c|c|c|c|c|}
\hline $\begin{array}{l}\text { Perspective taking } \rightarrow \text { White guilt } \rightarrow \\
\text { Collective action }\end{array}$ & $\begin{array}{l}\text { Unstandardized } \\
\text { beta }\end{array}$ & $\begin{array}{l}\text { Standard } \\
\text { error }\end{array}$ & $\begin{array}{l}\text { Standardized } \\
\text { beta }\end{array}$ & $t$ & $p$ \\
\hline $\begin{array}{l}\text { Step 1: Perspective taking } \rightarrow \text { White Guilt } \\
R^{2}: .15, F=22.95\end{array}$ & .28 & .06 & .30 & 5.08 & .0001 \\
\hline $\begin{array}{l}\text { Step 2: Perspective taking } \rightarrow \\
\text { Collective action } \\
R^{2}: .07, F=8.15\left[R^{2}: .05, F=5.72\right]\end{array}$ & .07 & .06 & .17 & 2.41 & .02 \\
\hline $\begin{array}{l}\text { Step 3: White guilt, controlling for } \\
\text { Perspective taking } \rightarrow \text { Collective action } \\
R^{2}: .05, F=5.92\left[R^{2}: .05, F=5.92\right]\end{array}$ & .11 & .05 & .13 & 1.95 & .05 \\
\hline $\begin{array}{l}\text { Step 4: Perspective taking, controlling for } \\
\text { White guilt } \rightarrow \text { Collective action } \\
R^{2}: .05, F=5.91\left[R^{2}: .05, F=5.91\right]\end{array}$ & .06 & .03 & .15 & 2.24 & .03 \\
\hline
\end{tabular}

participation in collective action. The indirect effect (Sobel, 1982) of perspective taking on collective action was significant $(z=-2.05$, $p<.05)$. Thus, when majority group members took the perspective of the minority group, they felt group-based guilt and were motivated to take action on behalf of the outgroup.

Group-based anger In light of an emerging interest in group-based anger, we also explored whether anger was directly or indirectly related to participation in collective action on behalf of an outgroup by regressing participation in collective action on participant gender and expressions of anger directed at the university administration. As in Study 1, anger at the university administration was directly related to collective action, $\beta=.13, p<.05$.

Given that anger at the administration was related to collective action, we also examined whether anger mediated the association between perspective taking and action. As in Study 1, we included gender as a covariate in these analyses. Perspective taking was not related to feelings of anger at the administration, $\beta=.06, p=n$ s. Since the first step of mediation was not met, we did not continue to test for mediation.

Finally, we examined whether feelings of group-based guilt continued to mediate when feelings of anger at the administration were in the equation. We regressed collective action on participant gender, outgroup perspective taking, group-based guilt, and group-based anger at the administration. The path from perspective taking to action remained significant, $\beta=.14, p<.05$. The path from group-based guilt to collective action, controlling for anger and perspective taking, remained significant, $\beta=.13, p=.05$. The path from group-based anger to collective action, controlling for guilt and perspective taking also remained significant, $\beta=.14, p<.05$. The indirect effect (Sobel, 1982) of perspective taking on collective action through group-based guilt was significant $(z=1.97, p<.05)$. Therefore feelings of group-based guilt continued to partially mediate between perspective taking and action, even when group-based anger was simultaneously entered as a predictor of collective action.

\section{Discussion}

Garnering additional support for our model, we found that perspective taking and groupbased guilt worked separately and in concert to influence collective action on behalf of an outgroup. That is, as perspective taking and feelings of White guilt increased so did participation in collective action. Moreover, White guilt mediated the relationship between outgroup perspective taking and action, further supporting our 
proposed model. Also, as in Study 1, although group-based anger was related to collective action, it did not mediate the association between perspective taking and action and did not affect the ability of guilt to explain participation in collective action.

Although our theoretically preferred model depicts White guilt as the mediator between perspective taking and participation in collective action, other causal orders are possible. For example, perspective taking may mediate the relationship between White guilt and collective action, or collective action may cause perspective taking, which could then produce feelings of group-based guilt. Tests of these two models indicated that they were viable alternatives to our theoretically preferred model.

Thus, the strength of our first two studies is that they compellingly demonstrate the associations between outgroup perspective taking, feelings of group-based guilt and participation in collective action in a real world setting. Yet the correlational nature of the studies leaves us unable to specify whether our model accurately accounts for collective action on behalf of outgroups. Because we believe that perspective taking causes feelings of group-based guilt and existing theory supports group-based guilt as a mediator between perspective taking and collective action, in Study 3 we manipulate perspective taking in order to test the causal nature of the associations. Since feelings of guilt consistently played a more significant role than feelings of anger in our studies, we refrain from examining group-based anger in Study 3.

\section{Study 3}

In Study 3, we extend the present research in three ways. First, and most importantly, we manipulate perspective taking to demonstrate its causal role in producing feelings of groupbased guilt and willingness to engage in collective action. We expect that asking Whites to take Blacks' perspective will cause feelings of White guilt and increase willingness to act on behalf of Blacks.

Second, as also proposed by Zebel et al. (2008), we again examine whether ingroup identification interacts with perspective taking to predict willingness to engage in collective action. Although we did not find that perspective taking and ingroup identification interacted to predict group-based guilt or collective action in Studies 1 and 2, we suspect this might be due to the fact that we measured the degree to which participants spontaneously took the outgroup's perspective rather than deliberately manipulating perspective taking. If encouraging people to take the outgroup perspective provides the necessary psychological kick to initiate actions to protect the positive image and status of the ingroup, then we might find that ingroup identification moderates the effect of deliberate perspective taking on group-based guilt and willingness to engage in collective action. If this is the case, then consistent with Zebel et al. (2008) we expect that when led to take the outgroup perspective, White's willingness to engage in collective action should increase to the extent that being White is unimportant to them (i.e. they lack identification with Whites). When not led to take the outgroup perspective, this relation should be absent.

Third, replicating Study 2, we test whether group-based guilt mediates the association between perspective taking and collective action. Validation of each prediction provides greater confidence regarding the veracity of our model of majority group member's collective action on behalf of a minority outgroup. Because feelings of group-based anger did not mediate the relationship between perspective taking and action in Studies 1 or 2, we no longer consider anger.

\section{Method}

Participants Forty-seven White students participated in the study in exchange for course credit.

Materials and procedure Participants were presented with a summary of hate crimes and acts of aggression that recently targeted Black students. Following Vescio et al. (2003), half of the participants read instructions to take the perspective of the targeted group while they read the summary: 
When reading about the incidents, pay careful attention to the content of the material, but try to step into the shoes of the African American student(s). Try to feel the full impact that the incident had on the student and imagine how he/she feels as a result.

The other half of the participants read instructions to remain objective as they read the summary:

When reading about the incidents, pay careful attention to the content of the material, but take an objective perspective. Try not to get caught up in how the people involved feel about the experience described or how it affected his/her life.

Then, all participants completed the five-item White guilt scale ( $\alpha=.88, M=3.39, S D=1.34$; Swim \& Miller, 1999) and reported the likelihood that they would engage in four types of collective action on behalf of African Americans on campus (Volunteer to put up fliers on grounds informing students of what has happened on grounds; Volunteer to hand out black ribbons at the next home football game; Obtain signatures for a University Judiciary Committee referendum to create specific and severe punishment guidelines for judicial offenses motivated by hatred based on race or ethnicity; Help to organize an event to show support of targets of discrimination). Each item was evaluated on a scale from 1, strongly disagree to 7, strongly agree. We averaged the items to form a composite measure of intention to engage in collective action $(\alpha=.78, M=4.01$, $S D=.128)$.

Finally, participants reported the extent to which they identified with Whites using 18 items (Swim \& Mallett, 2005; see Appendix for items). We averaged participants' responses to form a composite measure of ingroup identification $(\alpha=.86, M=4.19, S D=.74) .^{6}$

\section{Results and discussion}

Perspective taking As in Studies 1 and 2, we standardized all variables before conducting the analyses. We began by testing the association between outgroup perspective taking and willingness to engage in collective action. If deliberately encouraging participants to take an outgroup's perspective prompts identity maintenance processes, then we should find that ingroup identification moderates the effect of outgroup perspective taking such that perspective taking causes willingness to engage in action to increase as the importance of being White and therefore defending the ingroup decreases. In the control condition (no perspective taking), we did not expect White identification to influence willingness to act.

We tested whether perspective taking and identification with Whites interacted to predict willingness to engage in collective action on behalf of Blacks by regressing collective action on participant gender, ingroup identification, and perspective taking in step 1 , and the product of identification and perspective taking in step 2 . Perspective taking was coded $1=$ perspective taking and $-1=$ no perspective taking/control. Consistent with predictions, the change between step 1 and step 2 was significant, $R^{2}=.14$, $F(4,46)=2.39, p<.05$. Perspective taking and ingroup identification interacted to predict willingness to engage in collective action, $\beta=-.46$ (.20), $p=.03$. When Whites were asked to deliberately take Blacks' perspective, as White identification and perhaps concern for protecting the image of their ingroup decreased, willingness to engage in collective action increased, $\beta=-.80$ (.34), $p=.025$. In contrast, in the control condition (no perspective taking), White identification did not influence willingness to engage in collective action, $\beta=.12$ (.24), $p=n s$. Therefore, deliberately taking the outgroup perspective was necessary for Whites to be willing to act on behalf of Blacks, but it was more effective when Whites placed less value on their group membership. ${ }^{7}$

Group-based guilt We continued testing the proposed model by determining whether feelings of group-based guilt were directly related to willingness to participate in collective action by regressing willingness to act on White guilt, controlling for gender. As expected, White guilt and collective action were positively related, $\beta=.36$ (.13), $p=.01$. As reports of White guilt increased, so did willingness to participate in collective action. 
Mediation analyses Given that ingroup identification moderated the effects of perspective taking on White guilt and collective action, a conceptual replication of Study 2 entails conducting a mediated moderation analyses (Muller, Judd, \& Yzerbyt, 2005) to determine whether the experience of group-based guilt mediated the association between the perspective taking by White identification interaction and willingness to engage in collective action, controlling for gender. According to Muller et al. (2005), mediated moderation can occur when: (i) the perspective taking by group identification interaction predicts group-based guilt (the mediator) and group-based guilt predicts the dependent variable (willingness to engage in collective action), or (ii) group identification predicts group-based guilt and the group-based guilt by perspective taking interaction predicts the dependent variable, or both. Note that both the main effect and the interaction within the first or second part of the model described earlier must be met for mediated moderation to occur, and that only one of the two patterns described earlier are necessary to demonstrate mediated moderation.

As illustrated in Table 3, in step 1, the perspective taking by group identification interaction significantly predicted willingness to engage in collective action. In step 2, the interaction significantly predicted the experience of groupbased guilt. Finally, as required to meet the conditions of mediated moderation, in step 3 when group-based guilt and the guilt by perspective taking interaction were included, the perspective taking by group identification interaction no longer predicted willingness to engage in collective action. However, the experience of group-based guilt did significantly predict willingness to engage in collective action. A Sobel test confirmed the indirect effect was significant. Thus, mediated moderation was successfully demonstrated as condition 'i' discussed earlier was met. Taking Blacks' perspective caused feelings of White guilt that increased as White identification decreased. Feelings of White guilt then increased willingness to take action on behalf of Blacks. ${ }^{8}$ When not led to take the outgroup perspective, the subsequent relations were absent.

Given that both the proposed mediator, group-based guilt, and the outcome variable, willingness to engage in collective action, were measured, it is useful to examine the reverse mediator-outcome pathway. Results of the reverse mediator-outcome analysis revealed that

Table 3. White guilt mediates the association between the perspective taking by White identification interaction and willingness to participate in collective action (Study 3). Paths key to demonstrating mediated moderation are given in bold

\begin{tabular}{|c|c|c|c|c|c|c|}
\hline \multirow[b]{4}{*}{ Predictor } & \multicolumn{2}{|c|}{ Step 1} & \multicolumn{2}{|c|}{ Step 2} & \multicolumn{2}{|c|}{ Step 3} \\
\hline & \multicolumn{2}{|c|}{$\begin{array}{c}\text { (Criterion collective } \\
\text { action) }\end{array}$} & \multirow{2}{*}{\multicolumn{2}{|c|}{$\begin{array}{l}\text { (Criterion mediator) } \\
\text { Group-based guilt }\end{array}$}} & \multicolumn{2}{|c|}{$\begin{array}{c}\text { (Criterion collective } \\
\text { action) }\end{array}$} \\
\hline & \multirow[b]{2}{*}{$b(S E)$} & \multirow[b]{2}{*}{$p$} & & & \multirow[b]{2}{*}{$b(S E)$} & \multirow[b]{2}{*}{$p$} \\
\hline & & & $b(S E)$ & $p$ & & \\
\hline Perspective-taking (PT) & $-.26(.19)$ & .19 & $-.39(.18)$ & .04 & $-.05(.20)$ & .81 \\
\hline Identification (ID) & $-.34(.21)$ & .11 & $-.09(.20)$ & .65 & $-.14(.23)$ & .55 \\
\hline $\mathrm{PT} \times \mathrm{ID}$ & $-.46(.21)$ & .03 & $-.74(.20)$ & $<.0005$ & $-.138(.23)$ & .56 \\
\hline \multicolumn{7}{|l|}{ Mediator } \\
\hline \multirow{2}{*}{$\begin{array}{l}\text { Guilt } \\
\qquad \text { Mediator } \times P T\end{array}$} & & & & & $.54(.22)$ & .02 \\
\hline & & & & & \multicolumn{2}{|c|}{ Sobel test: $z=-2.05, p<.05$} \\
\hline Guilt $\times$ PT & & & & & $.29(.22)$ & .18 \\
\hline
\end{tabular}


in step 2, although intent to engage in collective action was a significant predictor of group-based guilt, $\beta=.39$ (.18), $p=.03$, the direct effect of the interaction remained significant, $\beta=-.57(.20)$, $p=.008$. Moreover, a Sobel test confirmed that the indirect effect was not significant $(z=-1.54$, $p=n s)$. This analysis provides strong support for our preferred theoretical model, demonstrating that feelings of group-based guilt partially mediate the relationship between the product of perspective taking and ingroup identification and willingness to participate in collective action on behalf of an outgroup.

\section{General discussion}

Past research has rarely considered factors that motivate majority group members to take collective action on behalf of minority group members, but investigating such factors is important and useful because of majority group members' unique ability to produce social change. We tested an initial model explaining majority group members' participation in collective action and found that outgroup perspective taking and the experience of groupbased guilt were key antecedents of actions that helped an outgroup.

Results consistently supported our predictions. We established that among heterosexuals and Whites, outgroup perspective taking was positively related to participation in collective action on behalf of the outgroup (Studies 1 and 2). We also found support for the link between White guilt and both willingness to engage, and actual participation, in collective action (Studies 2 and 3). Moreover, we demonstrated the efficacy of the full model by showing that White guilt partially mediated the association between perspective taking and both willingness to participate and actual participation in collective action on behalf of the outgroup (Studies 2 and 3 ).

In addition to testing our main predictions, we also furthered understanding of the role of ingroup identification in collective action on behalf of the outgroup. Exploratory analyses revealed that when we examined the effect of deliberately taking the outgroup perspective, outgroup perspective taking predicted feelings of group-based guilt and willingness to engage in collective action on behalf of the outgroup (Study 3). However, similar to the results of Zebel et al. (2004), the positive effect of deliberate perspective taking was most pronounced for those individuals who placed less value on being White. Specifically, when Whites took Blacks' perspective, this caused feelings of White guilt that increased as White identification, and perhaps concern for defending the ingroup, decreased (Study 3). White guilt then increased willingness to take action on behalf of Blacks; mediation did not occur when White participants did not take the perspective of Blacks. By contrast, when we examined spontaneous perspective taking (Studies 1 and 2), ingroup identification did not alter the affect of outgroup perspective taking on group-based guilt or collective action. We suspect that this occurred because deliberately encouraging outgroup perspective taking triggered identity maintenance processes among high but not low identified group members. For example, Doosje et al. (1998) found that people with high ingroup identification were resistant to threats to the positive image of the ingroup and reported less guilt than those who with low ingroup identification. By comparison, spontaneous outgroup perspective taking might not have made participants' group membership as salient and therefore may have failed to initiate the same type of identity maintenance processes.

Finally, although some research suggests that group-based anger may also influence participation in collective action, we found that groupbased anger played a limited role in initiating the form of collective action investigated in the current research. Although reports of groupbased anger at the university administration were directly related to participation in collective action (Studies 1 and 2), anger did not mediate the association between outgroup perspective taking and collective action. Perspective taking might not have related to the experience of group-based anger in Study 2 because it is unnecessary to see the world through the outgroup's eyes in order to appraise an action committed by another as blameworthy. In 
comparison, perspective taking is a necessary component of the experience of group-based guilt because seeing the world through the eyes of the outgroup contributes to one's understanding and appreciation of the harm done to the outgroup, which increases feelings of groupbased guilt that, in turn, lead to participation in collective action.

Importantly, feelings of group-based guilt continued to mediate the relationship between perspective taking and action even when feelings of group-based anger were included as a predictor of collective action. This might have occurred because feelings of guilt motivate people to repair damaged intergroup relations-the likely goal of collective action on behalf of an outgroup-whereas feelings of anger motivate people to confront or act against the perpetrator of a blameworthy action. It would be interesting in the future to examine whether the relative strength of group-based guilt and anger in predicting collective action vary as a function of how collective action is characterized. For example, group-based guilt might be more predictive of collective action that is characterized as a means of helping the minority outgroup, whereas group-based anger might be more predictive of collective action that is characterized as a means of rising up against the unjust aggressor.

It might also be worthwhile to consider the extent to which majority group members feel connected to the targeted minority group and therefore experience a dual identification. According to Gaertner and Dovidio's Common Ingroup Identity Model (Gaertner, Dovidio, Anastasio, Bachman, \& Rust, 1993), intergroup relations are often the most positive when majority and minority group members become aware of a shared superordinate group membership (e.g. we are all students at the same university). Recategorizing groups in this way improves intergroup attitudes and potentially facilitates positive intergroup contact by encouraging equal status, cooperation, and interpersonal interaction (Gaertner, Rust, Dovidio, Bachman, \& Anastasio, 1996). Taking the outgroup perspective could create a similar mindset if majority group members see the world through the eyes of a minority group member. Being less identified with the majority ingroup might further enable people to see the self as part of a shared superordinate group because they are not particularly motivated to protect the status of the ingroup.

In sum, we provided support for an initial model of collective action on behalf an outgroup as well as examined the relevance of ingroup identification and group-based anger. Future research could build upon our model by examining the possibility that other group-based emotions might further explain participation in collective action. Recent research suggests that group-based feelings of shame (Lickel, Schmader, \& Barquissau, 2004) might have interesting implications. For example, groupbased shame may manifest in distancing from ingroup members who caused the events or distancing from situations that remind people of the inequality (Lickel et al., 2004). If people distance from situations related to inequity, then shame might actually inhibit collective action. Future research could simultaneously assess other group-based emotions such as anger, shame and guilt to determine the unique power of each of these emotions to predict collective action taken on behalf of an outgroup, and to examine the extent to which each emotion serves to mediate the relationship between perspective taking and collective action.

Because of their larger numbers and greater relative power within society (Sidanius \& Pratto, 1999; H. J. Smith \& Tyler, 1996), majority group members play a key role in enacting social change on a broad scale. Our research represents an important step in understanding why majority group members participate in collective action on behalf of minority groups. Taking the minority group perspective inspires collective action in majority group members because of feelings of group-based guilt. Moreover, the impact of deliberate outgroup perspective taking on guilt and action increases as ingroup identification decreases, suggesting the possibility that different factors may increase guilt and action depending on ingroup identification. By seeing through the eyes of minority group members, majority group members can be inspired to take action 
in alliance with the minority group, which could perhaps reduce existing inequality more so than minority group members acting alone.

\section{Notes}

1. Participants completed several measures of attitudes, beliefs, and perceptions of the incidents for a different study. We unsuccessfully attempted to measure feelings of heterosexual guilt. Item analysis showed that the only reverse-scored item was positively correlated with the other items, suggesting that participants might not have understood the construct $(\alpha=.61)$.

2. It is possible to conceptualize collective action as dichotomous rather than continuous (i.e. whether participants took action or not). A logistic regression showed that, again, perspective taking was positively associated with participation in collective action, $\beta=.69, p<.001$. Heterosexuals that took non-heterosexuals' perspective were more likely to take collective action than those who did not. In both Studies 1 and 2, we also conducted logistic regression analyses for all analyses reported that used the participation in collective action dependent variable; the results were the same as those for the continuous variable.

3. In both Studies 1 and 2, we tested whether gender moderated the relationship between perspective taking, identification, anger, or guilt and participation in collective action; it did not.

4. It is interesting to note that, using the same analytic procedure as we did for collective action, identification did not moderate the degree to which perspective taking was related to anger, $\beta=.22, t(219)=.61, p=n s$.

5. Again, we tested whether identification moderated the influence of perspective taking on group-based guilt and anger by using the same two-step analytic strategy that we used for collective action. We did not find an interaction for guilt, $\beta=-.47, t(236)=-1.36, p=n s$, or anger at the administration, $B=-.26, t(236)=-.74$, $p=n s$.

6. An independent means $t$-test shows that identification did not differ by perspective taking condition, $t(45)=1.52, p=n s$. Whites who took Blacks' perspective did not report different levels of White identification than Whites who did not take Blacks' perspective.
7. We expected the same pattern for group-based guilt and conducted the same regression analysis to examine our prediction. As expected, perspective taking and ingroup identification interacted to predict group-based guilt, $\beta=-.74$ $(.20), p<.001$. When Whites were asked to take Blacks' perspective, group-based guilt increased as White identification decreased, $\beta=-.83$ (.30), $p=.008$. Therefore, given the lack of interaction between identity and perspective taking in Studies 1 and 2 and the presence of the interaction in Study 3, it appears that there is a critical distinction between spontaneous and deliberate outgroup perspective taking. Identification maintenance processes are only triggered when people are asked to deliberately take the outgroup perspective.

8. Some readers might argue that we could have tested for mediated moderation by separately conducting mediation analyses within the perspective taking and control conditions (or conversely within the low and high ingroup identification conditions). However, Muller et al. (2005) argue that is an inappropriate way of examining mediated moderation and that the full model we tested in Table 2 is appropriate. Nevertheless, to clarify the pattern of results, we tested mediation for the perspective taking condition and the control condition. We found that guilt mediated between identification and action in the perspective taking condition, but not in the control condition. Therefore, it seems that perspective taking provides the necessary kick to produce guilt and collective action.

\section{References}

Arsenault, R. (2006). Freedom riders: 1961 and the struggle for racial justice (Pivotal Moments in American History). New York: Oxford University Press.

Baron, R. M., \& Kenny, D. A. (1986). The moderator-mediator variable distinction in social psychological research: Conceptual, strategic and statistical considerations. Journal of Personality and Social Psychology, 51, 1173-1182.

Batson, C. D. (1998). Altruism and prosocial behavior. In D. T. Gilbert, S. T. Fiske, \& G. Lindzey (Eds.), The handbook of social psychology, Vol. 2 (4th ed., pp. 282-316). New York: McGraw-Hill.

Batson, C. D., Polycarpou, M. P., Harmon-Jones, E., Imhoff, H. J., Mitchener, E. C., Bednar, 
L. L., Klein, T. R., \& Highberger, L. (1997). Empathy and attitudes: Can feeling for a member of a stigmatized group improve feelings toward the group? Journal of Personality $\mathcal{E}$ Social Psychology, 72, 105-118.

Baumeister, R. F., Reis, H. T., \& Delespaul, P. A. (1995). Subjective and experiential correlates of guilt in daily life. Personality and Social Psychology Bulletin, 21, 1256-1268.

Branscombe, N. R., Doosje, B., \& McGarty, C. (2002). Antecedents and consequences of collective guilt. In D. M. Mackie \& E. R. Smith (Eds.), From prejudice to intergroup emotions: Differential reactions to social groups (pp. 49-66). Philadelphia, PA: Psychology Press.

Coke, J. S., Batson, C. D., \& McDavis, K. (1978). Empathic mediation of helping: A two-stage model. Journal of Personality and Social Psychology, 36, 752-766.

Czopp, A. M., \& Monteith, M. J. (2003). Confronting prejudice (literally): Reactions to confrontations of racial and gender bias. Personality E Social Psychology Bulletin, 29, 532-544.

Davis, M. H., Conklin, L., Smith, A., \& Luce, C. (1997). Effect of perspective taking on the cognitive representation of persons: A merging of self and other. Journal of Personality and Social Psychology, 70, 713-726.

Devos, T., Silver, L. A., Mackie, D. M., \& Smith, E. R. (2002). Experiencing intergroup emotions. In

D. M. Mackie \& E. R. Smith (Eds.), From prejudice to intergroup emotions: Differentiated reactions to social groups (pp. 113-134). Philadelphia, PA: Psychology Press.

Doosje, B., Branscombe, N. R., Spears, R., \& Manstead, A. S. (1998). Guilty by association: When one's group has a negative history. Journal of Personality and Social Psychology, 75, 872-886.

Dovidio, J. F., ten Vergert, M., Stewart, T. L., Gaertner, S. L., Johnson, J. D., Esses, V. M., Riek, B. M., \& Pearson, A. R. (2004). Perspective and prejudice: Antecedents and mediating mechanisms. Personality and Social Psychology Bulletin, 30, 1537-1549.

Estrada-Hollenbeck, M., \& Heatherton, T. F. (1998). Avoiding and alleviating guilt through prosocial behavior. In J. Bybee (Ed.), Guilt and children (pp. 215-231). San Diego, CA: Academic Press.

Finlay, K. A., \& Stephan, W. G. (2000). Improving intergroup relations: The effects of empathy on racial attitudes. Journal of Applied Social Psychology, 30, 1720-1737.

Frijda, N. H. (1986). The emotions. Cambridge, UK: Cambridge University Press.

Frijda, N. H. (1988). The laws of emotion. American Psychologist, 43, 349-358.

Gaertner, S. L., Dovidio, J. F., Anastasio, P. A., Bachman, B. A., \& Rust, M. C. (1993). The common ingroup identity model: Recategorization and the reduction of intergroup bias. In W. Stroebe \& M. Hewstone (Eds.), European Review of Social Psychology, 4, 1-26.

Gaertner, S. L., Rust, M. C., Dovidio, J. F., Bachman, B. A., \& Anastasio, P. A. (1996). The contact hypothesis: The role of a common ingroup identity on reducing intergroup bias among majority and minority group members. In J. L. Nye \& A. M. Brower (Eds.), What's social about social cognition? (pp. 230-360). Newbury Park, CA: SAGE.

Galinsky, A. D., \& Moskowitz, G. B. (2000). Perspective taking: Decreasing stereotype expression, stereotype accessibility and ingroup favoritism. Journal of Personality and Social Psychology, 72, 617-626.

Herek, G. M., Cogan, J. C., \& Gillis, J. R. (2002). Victim experiences in hate crimes based on sexual orientation. Journal of Social Issues, 58, 319-339.

Iyer, A., Leach, C. W., \& Crosby, F. J. (2003). White guilt and racial compensation: The benefits and limits of self-focus. Personality and Social Psychology Bulletin, 29, 117-129.

Iyer, A., Schmader, T., \& Lickel, B. (2007). Why individuals protest the perceived transgressions of their country: The role of anger, shame, and guilt. Personality and Social Psychology Bulletin, 33, 572-587.

Jones, E. E. (1976). How do people perceive the causes of behavior? American Scientist, 64, 300-305.

Klandermans, B. (2002). How group identification helps to overcome the dilemma of collective action. American Behavioral Scientist, 45, 887-900.

Lazarus, R. S. (1991). Emotion and adaptation. London: Oxford University Press.

Leach, C. W., Iyer, A., \& Pedersen, A. (2006). Guilt and anger about in-group advantage as explanations of the willingness for political action. Personality and Social Psychology Bulletin, 32, 1232-1245. 
Leach, C. W., Snider, N., \& Iyer, A. (2002).

'Poisoning the consciences of the fortunate':

The experience of relative advantage and support for social equality. In I. Walker \& H. J. Smith (Eds.), Relative deprivation: Specification, development, and integration (pp. 136-163). New York: Cambridge University Press.

Leith, K. P., \& Baumeister, R. F. (1998). Empathy, shame, guilt, and narratives of interpersonal conflicts: Guilt-prone people are better at perspective taking. Journal of Personality, 66, 1-37.

Lickel, B., Schmader, T., \& Barquissau, M. (2004). Aspects of social identity in the experience of collective guilt and shame. In N. R. Branscombe \& B. Doosje (Eds.), Collective guilt: International perspectives (pp. 35-55). New York: Cambridge University Press.

Liss, M., Crawford, M., \& Popp, D. (2004). Predictors and correlates of collective action. Sex Roles, 50, 771-779.

Mackie, D. M., Devos, T., \& Smith, E. R. (2000). Intergroup emotions: Explaining offensive action tendencies in an intergroup context. Journal of Personality and Social Psychology, 79, 602-616.

Maitner, A. T., Mackie, D. M., \& Smith, E. R. (2006). Evidence for the regulatory function of intergroup emotion: Implementing and impeding intergroup behavioral intentions. Journal of Experimental Social Psychology, 42, 720-728.

Mallett, R. K., \& Swim, J. K. (2004). Collective guilt in the United States: Predicting support for social policies that alleviate social injustice. In N. R. Branscombe \& B. Doosje (Eds.), Collective guilt: International perspectives (pp. 56-74). New York: Cambridge University Press.

Mallett, R. K., \& Swim, J. K. (2007). The influence of inequality, responsibility, and justifiability on reports of group-based guilt for ingroup privilege. Group Processes $\mathcal{E}^{2}$ Intergroup Relations, 10, 57-69.

McAdam, D. (1982). Political process and the development of black insurgency, 1930-1970. Chicago: University of Chicago Press.

McPherson, F. C., \& Janoff-Bulman, R. (2000). Considering both sides: The limits of perspective taking. Basic $\mathcal{E}$ Applied Social Psychology, 22, 31-42.

Miceli, M. (2005). Standing out, standing together: The social and political impact of gay-straight alliances. New York: Routledge.
Montada, L., \& Schneider, A. (1989). Justice and emotional reactions to the disadvantaged. Social Justice Research, 3, 313-344.

Muller, D., Judd, C. M., \& Yzerbyt, V. Y. (2005). When moderation is meditated and when mediation is moderated. Journal of Personality and Social Psychology, 89, 852-863.

Ortony, A., Clore, G. L., \& Collins, A. (1988). The cognitive structure of emotions. Cambridge, UK: Cambridge University Press.

Sidanius, J., \& Pratto, F. (1999). Social dominance: An intergroup theory of social hierarchy and oppression. Cambridge, UK: Cambridge University Press.

Smith, E. R. (1993). Social identity and social emotions: Toward new conceptualizations of prejudice. In D. M. Mackie \& D. L. Hamilton (Eds.), Affect, cognition, and stereotyping: Interactive processes in group perception (pp. 297-315). San Diego, CA: Academic Press.

Smith, H. J., \& Tyler, T. R. (1996). Justice and power: When will justice concerns encourage the advantaged to support policies which redistribute economic resources and the disadvantaged to willingly obey the law? European Journal of Social Psychology, 26, 171-200.

Sobel, M. E. (1982). Asymptotic intervals for indirect effects in structural equations models. In S. Leinhart (Ed.), Sociological methodology (pp. 290-312). San Francisco: Jossey-Bass.

Swim, J. K., \& Mallett, R. K. (2005). Validation of a scale to assess identification with ingroups and outgroups. Manuscript in preparation.

Swim, J. K., \& Miller, D. L. (1999). White guilt: Its antecedents and consequences for attitudes toward affirmative action. Personality E Social Psychology Bulletin, 25, 500-514.

Taylor, D. M., \& McKirnan, D. J. (1984). A five-stage model of intergroup change. British Journal of Social and Clinical Psychology, 23, 291-300.

Underwood, B., \& Moore, B. (1982). Perspective-taking and altruism. Psychological Bulletin, 91, 143-173.

Van Zomeren, M., Spears, R., Fischer, A. H., \& Leach, C. W. (2004). Put your money where your mouth is! Explaining collective action tendencies through group-based anger and group efficacy. Journal of Personality and Social Psychology, 87, 649-664.

Vescio, T. K., Sechrist, G. B., \& Paolucci, M. P. (2003). Perspective taking and prejudice reduction: The mediational role of empathy 
arousal and situational attributions. European Journal of Social Psychology, 33, 455-472.

Wright, S. C., \& Tropp, L. R. (2002). Collective action in response to disadvantage: Intergroup perceptions, social identification, and social change. In I. Walker \& H. J. Smith (Eds.), Relative deprivation: Specification, development, and integration (pp. 200-236). New York: Cambridge University Press.

Zebel, S., Doosje, B., \& Spears, R. (in press, 2008). How perspective-taking helps and hinders group-based guilt as function of group identification. Group Processes $\mathcal{E}$ Intergroup Relations.

Paper received 17 November 2006; revised version accepted 31 April 2008.

\section{Biographical notes}

ROBYN K. MALLETT is an assistant professor of psychology at Loyola University Chicago. Her research focuses on topics related to intergroup relations and social justice. She is currently investigating ways to optimize intergroup contact and minimize the consequences of discrimination.

JEFFREY R. HUNTSINGER is a lecturer at Loyola University Chicago. His research focuses on motivational and affective influences on cognition. He is currently exploring how affect shapes automatic processing.

STACEY SINCLAIR is currently an associate professor of psychology at the Princeton University. She is interested in how interpersonal interactions, and the beliefs we attribute to others, shape our beliefs, feelings and actions-particularly those beliefs relevant to stereotyping and prejudice.

JANET K. SWIM is a professor of psychology at the Pennsylvania State University. Currently, she is examining topics such as accuracy in judgments about who is prejudiced and meta-perceptions of prejudice, the role of goals in coping with discrimination, and barriers to and facilitation of pro-environmental behaviors.

\section{Appendix}

\section{Identification items}

Whites [Heterosexuals] have much to be proud of these days.

I think that I am very different from most Whites [Heterosexuals].

I have spent time trying to find out more about White [Heterosexual] culture, such as the history of Whites [Heterosexuals] in America.

I don't have a lot in common with Whites [Heterosexuals].

I have difficulty identifying with the culture of White Americans [Heterosexuals].

I really have not spent much time trying to learn more about the culture of Whites [Heterosexuals], such as their history and traditions.

I am very concerned about the problems Whites [Heterosexuals] have in today's society.

When electing public officials, I would vote for candidates who I know consider issues that affect White Americans [Heterosexuals].

I feel an attachment to Whites [Heterosexuals] as a group.

I seek out information about the culture of Whites [Heterosexuals]

When I meet a White person [Heterosexual], I feel like I will have a lot in common with him or her.

I think a lot about how White people's [Heterosexuals] lives will be affected by their ethnic group membership.

I feel little sense of commitment to White people [Heterosexuals] even those who are close friends.

I think I have much in common with Whites [Heterosexuals].

I have learned a lot about the history and tradition of Whites [Heterosexuals].

I don't actively seek out news and information on issues affecting Whites [Heterosexuals] in America.

I feel that it is important to keep up with issues that are important to Whites [Heterosexuals] in America.

I'm aware of the types of daily events Whites [Heterosexuals] tend to experience these days. 